\title{
Title: -To study the selective potentiality and anti-tumor activity of CAP in oral cancer treatment.
} Swapnil Dey ${ }^{(1)}$, Rachana Phadke ${ }^{(2)}$, Dattatreya Mukherjee*(3) ${ }^{*}$ Debraj Mukhopadhyay ${ }^{(4)}$

1. Dept of Zoology, Cotton University, Guwahati, India

2. Indira Gandhi Government Medical College, Nagpur, India

3. Jinan University, Guangzhou, P.R China

4. Department of Public Health, School of Allied Health Sciences, Delhi Pharmaceutical Sciences and Research University (DPSRU), Govt. of N.C.T Delhi, New Delhi, India

Corresponding Author: Dattatreya Mukherjee, dattatreyamukherjee4u@outlook.com

Non funded project and Authors have no Conflict of Interest

Abstract: - Oral Cancer is one of the leading causes of death in India, specifically in its Northeastern region. India holds about one third cases of the total oral cancer in the world. According to a report (2018), India holds 1,19,992 new cases of oral cancer and 72,616 deaths. Current approaches in cancer treatment mainly include surgery, chemotherapy and radiation therapy. These treatments often give a morbid outcome and reduce survival rate. This is mainly due to their non-selective nature to kill the tumor cells along with the normal cells. Recently the potential of Cold Atmospheric Plasma (CAP) in cancer treatment is gaining great interest among scientists and researchers. This is mainly due to the enhanced selective nature of the CAP in targeting and killing the tumor cells without affecting the surrounding tissue and causing minimal side effects. Reactive Oxygen and Nitrogen species (RONS) are the main contributors of the efficacy of CAP in killing cancer cells. Although many attempts have been made to understand the underlying mechanism of CAP in cancer treatment, there is a lack of detailed studies with respect to different treatment conditions. The use of CAP can be a potential innovative therapy in the upcoming days and more clinical trials should be encouraged to prove its efficacy and relevance in clinical purpose.

\section{Introduction and Background}

Cancer is one of the biggest health care issues faced by mankind of this century. According to National Institute of Cancer Prevention and Research (NICPR), estimated number of people living with disease in India is around 2.25 million[1].Oral cancer is one of the leading causes of death in cancer patients. Although distributed globally, this cancer type is more prevalent in South Central Asia. India contributes to about one-third of the total global cases. The death-toll of the disease in 2018 was 72,616. Statistically, this is a very devastating number.[2] 
Oral cancers are a group of neoplasms mainly affecting the oral cavity, salivary glands and some parts of pharyngeal region. The term "oral cancer" often tends to get replaced with oral squamous cell carcinoma (OSCC) which is most frequent among all other oral neoplasms. It is reported that around $>90 \%$ of all oral neoplasms are OSCC [3]. The most common and recent types of cancer treatments include surgery, chemotherapy and radiation therapy. Surgery is the most common approach in oral cancer followed by chemotherapy and rarely radiotherapy.

Despite the many advances in therapeutic approaches and the availability of several interventions, the morbidity and mortality rates seem to be unchanged. This is mainly due to the non-selective nature of these therapeutic approaches, killing the tumor cells as well as healthy cells, reducing the patient survival rate to a great extent [4]. Thus, the current situation demands a proactive strategy to develop an effective cure with minimal side effects.

Recently, the fourth state of matter i.e. plasma has been used in a wide range of applications in biomedical field. More precisely, non-thermal plasma (NTP) has gained much popularity in recent times in the domain of cancer therapy by using cold plasma due to its selective nature to kill tumor cells [4]. It has become a novel treatment method for various cancers including oral cancer, lung cancer, melanoma and colorectal cancer. NTPs are actually a cocktail of ionized gas with electrons, ions, neutral atoms, radicals, and UV photons. NTPs mainly work by inducing apoptosis via the signaling pathway, inhibiting cell invasion and migration, or by arresting the cell cycle. Devices such as plasma jets are used to treat the tumor cells effectively. [5-6]

However, there still is not much promising clinical evidences about cold plasma therapy in oral cancer but still this unique synergistic approach of physical science with that of biological domain is believed to add a major contribution in the field of cancer treatments in near future with minimal side effects, low cost and less time consumed. Thus, it is necessary to get a comprehensive idea about the mechanism of action and effectiveness of NTPs in oral cancer tissues.

Therefore, in this review we discuss the mechanism of action and potential efficacy of NTPs in treating oral cancer tissues specifically along with its side effects and clinical significance.

4.Objectives and Review of Literature-This review project aims to highlight and discuss the mechanism of CAP treatment in oral cancer cells and to get an insight of the various pathways triggered during the CAPs exposure to target cell lines. The literature of this review can be discussed under the following heads:

A) ATMOSPHERIC PRESSURE PLASMA JET DEVICE-Most of the plasma jets are released into the surrounding environment by devices that internally generate non-thermal plasmas (NTP). The plumes are blown out of the device by gases that flow typically at several liters per minute. NTPs are generated with various combinations of electrode geometries and along with a variety of frequencies ranging from DC to Microwave.[6] 


\section{OSF PREPRINTS}

Typically, a plasma jet consists of a wire electrode (mostly copper), a glass confinement tube with $8 \mathrm{~mm}$ inner diameter and $10 \mathrm{~mm}$ outer dimeter(approx.), a Teflon fitting and a pencil-shaped nozzle having $2 \mathrm{~mm}$ inner diameter at the exit. A sharp tipped tungsten pin wire $(0.3 \mathrm{~mm}$ diameter) is placed on the tube axis and the nozzle is attached to the glass tube end.[7]

Most often, in an attempt to increase the concentration of reactive species for cell treatment, another kind of plasma jet with improved jet source is designed. This plasma jet has a copper wire electrodes( $2 \mathrm{~mm}$ diameter), polyetheretherketone (PEEK) plastic housing and a pencilshaped grounded ring-electrode(copper, 6-mm inner diameter and 16-mm outer diameter at the exit) covered with dielectric PEEK. The wire is normally inserted coaxially in the housing and covered with a Teflon tube, with $6 \mathrm{~mm}$ of the wire exposed to gas and being surrounded by the ground electrode. This small distance between the powered and grounded electrodes aids in the local enhancement of the electric field and reduces breakdown voltage requirement, compared to the plasma jets utilizing annular ring electrode or dielectric barrier discharge jets.[8,9]

Usually, the copper tube is connected to the high voltage power supply(preferably, $20-25 \mathrm{kHz}$ in DC or AC power supply with the voltage of $5 \mathrm{kV}$ ) and the copper ring being connected to the ground .Helium or Argon gas is generally the preferred carrier gas chosen with an approximate flow rate of 3-4s $\mathrm{sm}$. Sometimes a flowmeter is preferred so as to ensure uniform and vigorous mixing of the medium during the plasma treatment. The range of plasma plume length is maintained at $(22 \pm 1) \mathrm{mm}$ and the distance between the nozzle and the cell surface is around 10-15 mm depending on other physical conditions. 


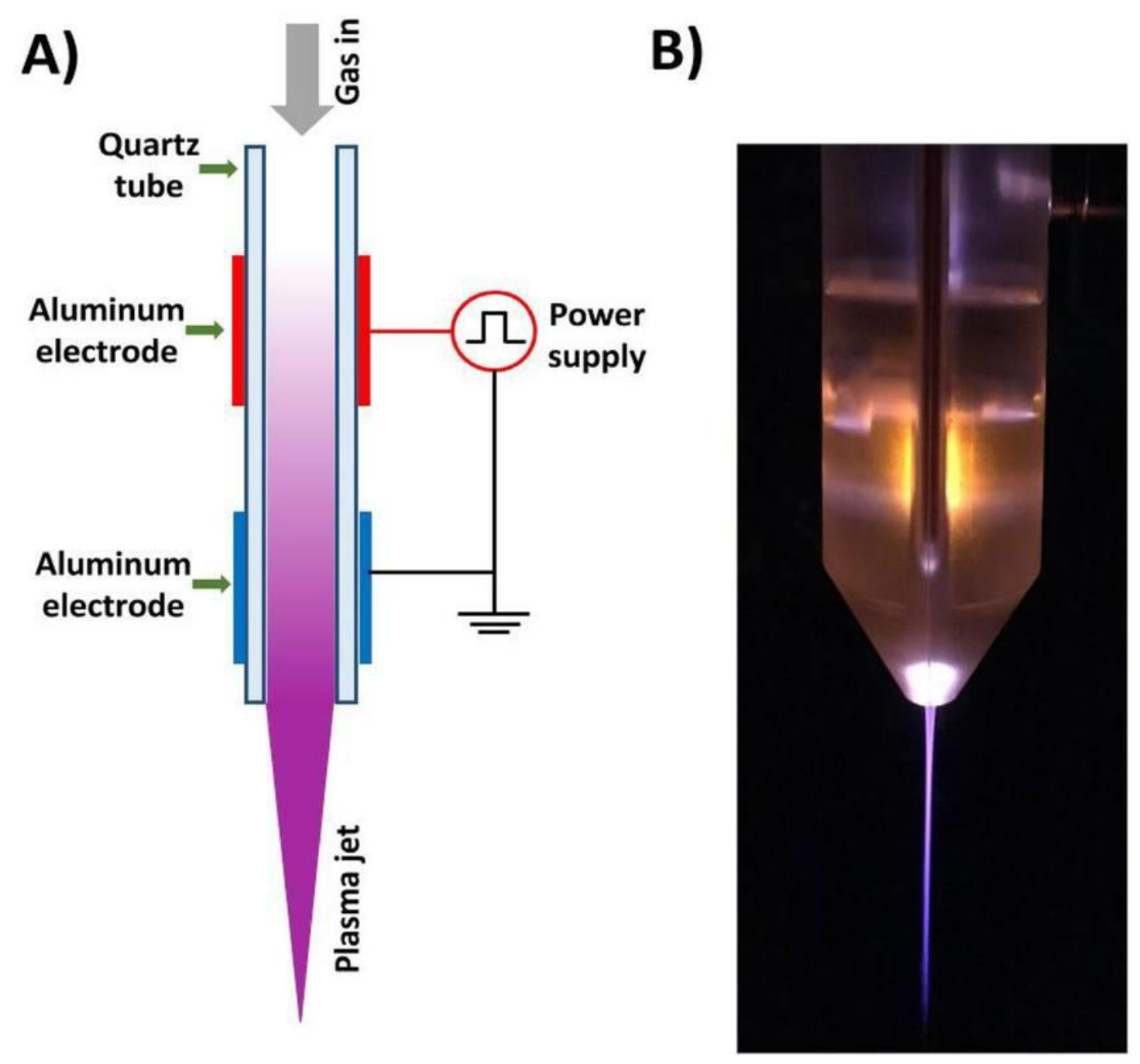

FIG1: A)Schematic diagram of a plasma jet. B)Actual picture of a plasma jet.[10]

\section{B). SELECTIVE ACTIVITY OF CAP ON TUMOR CELLS}

Several studies showed the selective nature of NTP treatment between the malignant and the non-malignant cells. Yan et al. in his studies found that 26 of 33 assessed cell lines showed a strong selectivity, 5 of 33 a weak selectivity while only 2 of 33 showed a negative selectivity [11]. However, the cell lines compared in his studies didn't necessarily belong to the same cell type or origin. A recent study by Bishop et al. (2019) showed that the cell type, cancer type and culture conditions significantly influence CAP treatment and hence need to be considered when selective activity of CAP is studied [12]. Furthermore, all these factors are preferably kept identical for a convenient result.

The difference between a malignant and a non-malignant cell may explain the CAPs selective activity on cancerous cells.[13]. Normally, the cancer cells are likely to be more sensitive, compared to healthy cells, in terms of oxidative stress. This can be explained taking into account 
the concept of aquaporins present on the cell membrane. Aquaporins are generally found more in cancer cells [14]. These are considered as water channels that often facilitate the transport of free oxygen and nitrogen species, such as hydrogen peroxide as well as other small molecules including $\mathrm{CO}_{2}$, NO etc. $[15,16,17]$. The pore size of these channels determines the passage of the reactive species and other molecules. Currently, Aquaporin 1,3 and 8 are known to play role in transport of $\mathrm{H}_{2} \mathrm{O}_{2}$ in mammalian cells [19]. Studies show that over-expression of aquaporins increases oxidative stress due to rising intracellular ROS concentration. [18,20] Furthermore, monitoring the intracellular hydrogen peroxide content shows that the tumor cells accumulate $\mathrm{H}_{2} \mathrm{O}_{2}$ faster than the non-malignant ones.

Besides this, cholesterol, which is the most abundant lipid in plasma membrane of animal cells also plays role in creating oxidative stress. The diffusion of reactive species depends on the amount of the cholesterol in the cell membrane. Higher concentration found in healthy cells acts as a barrier to reactive species while lower level in tumor cells makes it more vulnerable to oxidative stress. If the intracellular oxidative stress triggered by free radicals exceeds the amount that can be handled by the anti-oxidative defense system apoptosis will be induced through a signaling cascade [21]. The permeation of RNS and ROS are found to be across lipid bilayer. $\mathrm{RNS}\left(\mathrm{NO}, \mathrm{NO}_{2}, \mathrm{~N}_{2} \mathrm{O}\right)$ penetrate more easily than $\mathrm{ROS}\left(\mathrm{H}_{2} \mathrm{O}_{2}, \mathrm{OH}, \mathrm{OH}_{2}\right)$.Studies reveal that, low NO concentrations is associated with chemo-resistance, anti-apoptosis, proliferation, metastasis, reduced immune response and angiogenesis while high $\mathrm{NO}$ is associated with apoptosis, antiproliferation, anti-angiogenesis, anti-metastasis, and immune response [22,23].High levels of NO in cancer cells in addition to CAP generated RNS may overwhelm the system and turn on the NO effect from tumor-promoting to tumor-suppressing.

\section{MECHANISM TRIGGERING CELL DEATH IN ORAL CANCER}

As discussed earlier, CAP is composed of RONS, charged particles, UV radiation and electromagnetic fields. All these synergistically act on the tumor cells. But the main factor that contributes to cell death in oral cancer cells upon CAP treatment is the ROS and RNS. [24]. The most prominent effect of RONS on cell membrane is lipid peroxidation. The free radicals form a pore in the membrane, which causes influx of reactive species into the cytoplasm. $\mathrm{Ca}^{2+}$, an important intra- and extracellular secondary messenger, is well known for its intricate association with ROS and calcium signaling.[25]. Increased intracellular ROS further interacts with inositol triphosphate receptor (IP3-RR) and ryanoid receptor (RR) and interferes with calcium signaling resulting in increased calcium influx into cytosol. Endoplasmic reticulum (ER) is the main source of increasing cytoplasmic calcium. An increase in ROS and a rapid release of calcium from the ER into the cytosol leads to ER stress [26]. ROS induced ER stress further leads to calcium influx into mitochondria reducing the membrane potential, followed by inducing mitochondria dependent apoptosis [27-36]. Unlike ROS, the impact of RNS is lesser known. It is expected that tissue damaging effects of $\mathrm{NO}$ are not clear [37]. 


\section{OSF PREPRINTS}

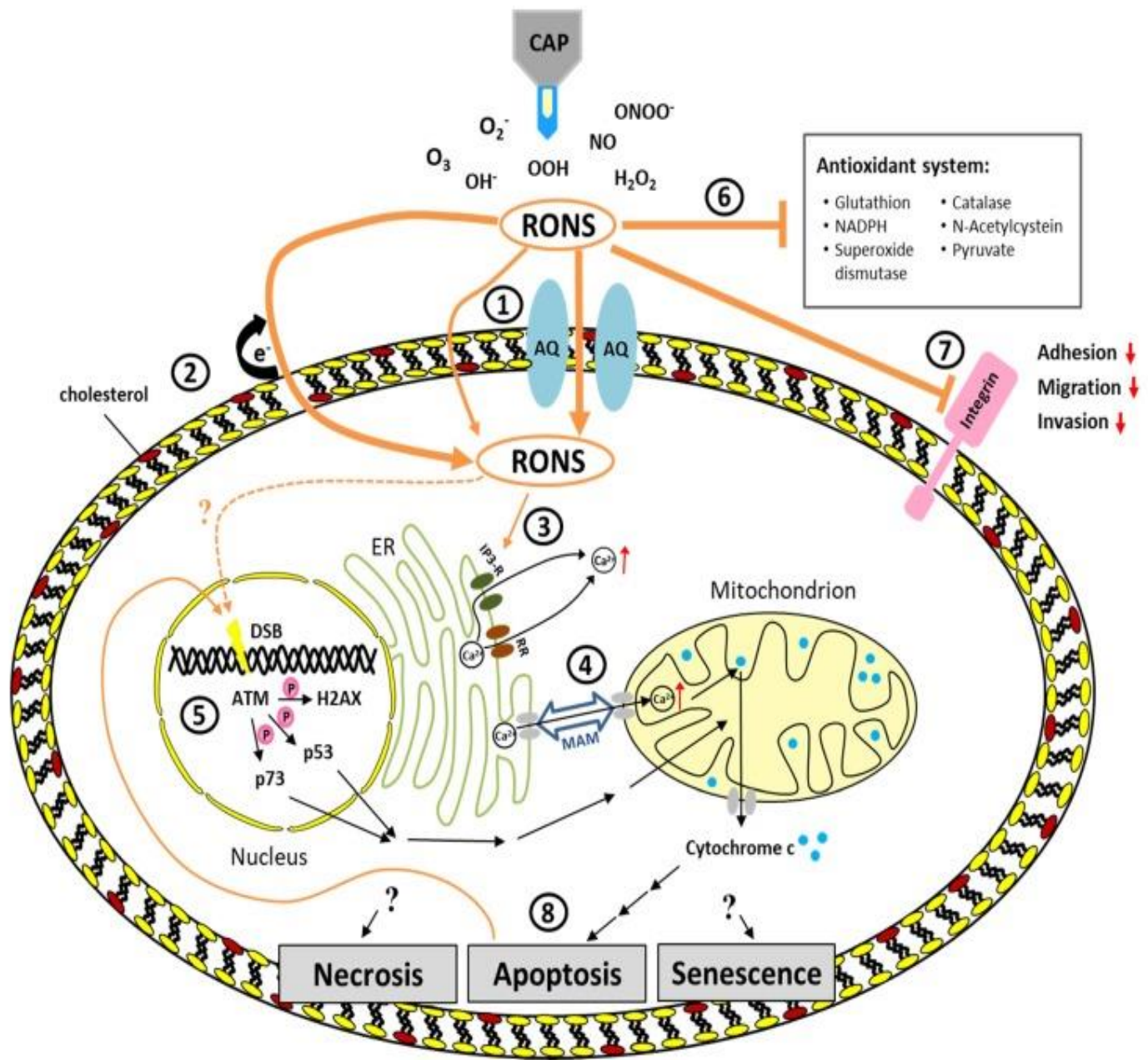

FIG 2: Schematic representation of pathways triggered by CAP treatment [75]

Apart from ROS and calcium signaling, an increase in RONS is also responsible for the induction of DNA lesions. Such DNA lesions include oxidative damage, DNA single strand and DNA double strand breaks (DSB) [37-39], DNA crosslinks and crosslinks between DNA and proteins [40]. Free radicals are also responsible for modifications of purine and pyrimidine rings, strand cleavage and chromosomal abnormalities [41-43]. Several studies showed DNA damage as a consequence of CAP treatment. However, in many studies primarily DSB have been assessed by detection of $\gamma \mathrm{H} 2 \mathrm{AX}$, a phosphorylated form of the histone $\mathrm{H} 2 \mathrm{AX}$. Phosphorylation of H2AX serves as a well-established indirect marker for DSB. The induction of DSB by CAP depends on the distance between the CAP source and the cells. In addition, the time of treatment is considered as well [44]. It is witnessed that a 30sec treatment led to DSB in $60 \%$ of oral cancer cells while treatment for $120 \mathrm{~s}$ induced DSB in $80 \%$ of the cells. Interestingly, this increase in DSB was first detected $72 \mathrm{~h}$ post-treatment. As H2AX is phosphorylated by the ataxia telangiectasia mutated (ATM) kinase, an increased expression of this kinase has been observed 
after CAP treatment in oral cavity squamous cell carcinoma cells [45]. However, activation of other substrates of ATM involved in signaling apoptosis such as p53 and p73 has also been observed in oral cavity squamous cell carcinoma and melanoma cells $[46,47,48]$.

Furthermore, the importance of ATM for apoptosis induction in response to DNA damage has been shown by small interfering (siRNA) knockout experiments. Knockout of ATM resulted in a prominent reduction of apoptosis in oral carcinoma cells [49]. Despite these results, DSB may not be a direct effect of CAP mediated low-ROS on DNA but rather a consequence of CAP induced apoptosis. The different modes of growth, arrest and cell death such as apoptosis, necrosis, senescence as well as autophagy have been observed as a consequence of CAP treatment. Although, various studies show a clear dose dependency, other factors such as cell type and plasma source may also influence the outcome. Further studies are required to decipher the exact molecular mechanisms and pin point which of these processes will be induced in response to a disturbed redox balance caused by CAP treatment.

\section{D) INTERACTION BETWEEN CAP AND THE TUMOR MICROENVIRONMENT}

It is very important to not only understand the interactions between plasma and the tumor cells, but also the relationship to the tumor microenvironment (TME) in order to understand the effect of plasma. The tumor microenvironment plays a vital role in cell growth, proliferation, survival, invasion and metastasis of the tumor cells. Furthermore, the TME also plays a crucial role in studying the efficacy of various chemotherapies. The effects of CAP have been observed on different parts of the tumor microenvironment, which is majorly composed of malignant cells, immune cells, endothelial cells, fibroblasts, tumor vasculature and the extracellular matrix, which are in constant communication with each other. However, in addition to that there are other cell types the TME consists of, such as collagen, elastin, fibronectin, glycoproteins, an d proteoglycan .Studies showed that prolonged treatment with CAP inhibits cell viability and collagen production of murine fibroblasts[47,49,55] .However, at the same time, in vitro studies have shown that CAP is able to destroy collagen . It is also reported that high doses of CAP prevent extracellular matrix interactions with cells and bone formation (Eisenhauer et.al). The desmoplastic reaction that has already been shown in the clinical use of CAP for the treatment of head and neck cancer also suggests an increased deposition of collagen [76,77]. Other components of the extracellular matrix, such as hyaluronic acid or fibronectin, can also be damaged or influenced by ROS, although a clearer investigation is required in this aspect. It is observed that some cells retain damage from plasma treatment even though they are not treated directly. Here, the bystander effect enables cells to send signals to untreated neighboring cells. Thus, soluble molecules such as chemokines, growth factors and different junctions can be used. The oxidative stress created by plasma treatment, influences or damages these signaling molecules. Also, apoptosis may occur in neighboring cells due to the formation of secondary oxygen and the inactivation of the membrane-bound catalase. It is also 
evident that calcium ions can be transported from apoptotic to neighboring non-apoptotic cells via gap junctions, which also explains the widespread effect of plasma. [23,28,44,46]

\section{E) IMMUNOGENIC RESPONSE ON CAP TREATMENT}

It was the Nobel Prize in Medicine or Physiology (2018) for checkpoint cancer immunotherapies that highlighted the importance of the immune system as a vital contributor to target tumor cells [108]. As the plasma treatment is a local therapy that possibly modulates the tumor microenvironment, various reports claim the possibility of plasma to stimulate immunity to support anticancer treatment. Recently, two lines of research are going on in parallel to disentangle the effect of plasma treatment in anticancer immunity. One is the ability of plasma to affect immune cells directly, which leads to their activation or selection of specific subpopulations of immune cells, while the other is an indirect activation of immune cells via plasma-mediated tumor cell death and pro-inflammatory signals in the microenvironment $[50,51,52]$.

Cellular immunity comprises of innate and adaptive immune cells. Phagocytes like the neutrophils, dendritic cells, and macrophages are some of the primary cell types that shape innate immune responses [53] For neutrophils, there is increasing evidence that their increased presence in tumors and blood is associated with poor prognosis in cancer patients [54].To date, there is only a single report on plasma-treated neutrophils that describes elevated neutrophil extracellular-trap (NET) formation in response to gas plasma treatment [55] Plasma-treated cell line-derived macrophages were shown to have a higher migratory activity [56], cytokine release [57], and augmented antitumor toxicity [58], which contributed to elevated levels of TNF $\alpha$ [59] when investigated in trans well co-culture systems. However, for other innate immune cells, such as NK cells or mast cells, no reports exist in the context of cancer immunology. Although, for primary NK cells, it is only known that they are similarly sensitive to plasma-induced cell death compared to adaptive lymphocytes, while activated NK cells are less prone to plasma-mediated apoptosis [60]. Similarly, only very few reports have reported response of cells of the adaptive immune system with regard to activation putatively important to anticancer immunity. While activated primary T-cells were also found less sensitive to apoptosis following exposure to plasma [61]. Interestingly, T-cells actively counteract plasma-mediated oxidative stress [62] while increasing markers associated with their activation such as CD69 and HLA-DR [63]. For both innate and adaptive immune cells, plasma treatment regulated the protein content of microparticles released from these cells [64], with microparticles being a biological entity increasingly recognized in cancer research [65].

Furthermore, extensive plasma treatment times or energies, damage tumor cells and there is an increasing evidence that such oxidation-induced cell death takes place in a pro-immunogenic manner. The paradigm of immunogenic cancer cell death (ICD) predicts that tumor antigens 
presented in an immunogenic but not tolerogenic context orchestrate antitumor T-cell responses [66]. Using direct plasma treatment or plasma-conditioned liquids, ICD has been observed in vitro in a number of tumor cell types including, for instance, pancreatic cancer, colorectal cancer, lung cancer, and malignant melanoma . Due to the extensive poly-pragmasia of plasma sources used in the field of plasma medicine, the central mechanisms underlying plasma-induced ICD have not been commonly unraveled. One of the sources initiating ICD is a dielectric barrier discharge used by Lin et al. The authors elegantly demonstrated a strong dependence of ICD on short-lived reactive species with an only minor contribution of other plasma effectors. However, the exact types of the main species being critical for plasma-induced ICD that would allow optimization of an anti-cancer plasma source specifically targeting ICD pathways were not identified. Moreover, the plasma source is not accredited as medical device, hampering translational efforts of this innovative therapy. For the accredited plasma medical device kINPen, clinical evidence has been reported in the therapy of stage IV head and neck cancer patients. However, all these data suggest that plasma treatment of tumor cells shapes antitumor immunity, although the extent of such an effect is subject to further research. [67-74].

\section{F) Clinical significance of CAP in current cancer treatment-}

Both in vitro and in vivo studies with cell line and animal models showed a huge potential of CAP for cancer treatment. But to study for its clinical significance, the efficacy ultimately has to be proven for human patients in a clinical setting. The first experiences have been reported from treating locally advanced head and neck cancers in six patients. A plasma jet (kINPen MED) is used to treat these patients for within one week in three cycles of single applications. This treatment resulted in improved quality of life in trial patients through a reduction in odor and pain medication demands. However, two patients showed a partial remission for at least nine month and biopsies from tissues in remission revealed a moderate amount of apoptotic tumor cells. Furthermore, similar results have been reported in a second study with 12 patients [76,77]. An analyses of resected CAP-treated tumor tissue showed an increase of apoptotic cells compared to non-treated tissue []. Another case study elucidated the effect of CAP on actinic keratosis (precursor lesions of squamous cell carcinomas)]. A total of 17 lesions have been treated in this study. Out of 17, 9 lesions showed total remission while 3 a partial remission and only 5 lesions showed only minimal or no improvement one month after CAP treatment. However, to note, no negative effects such as inflammation, pain, or other adverse events have been observed neither during treatment, immediately after treatment nor in the later course of the disease. Althogh more patients need to be treated, but however more than $70 \%$ of these patients responded to the therapy positively. [56,58,60]

In a second study with seven patients with actinic keratosis, all patients showed a good response with a significant remission of the actinic keratosis after seven treatments for $120 \mathrm{~s}$ using a plasma jet. Furthermore, a pilot study including eight patients with malignant pleural mesothelioma investigated the use of cold plasma for cold plasma coagulation (CPC). The histological examinations of pleural specimens revealed no detectable vital tumor cells in deeper 
layers of the pleural and subpleural space. Also, no relapse of the disease was observed during the time of the study (median observations time was one year). Although these first clinical reports are very convincing, they can only be the beginning of further clinical trials. However, more clinical research and studies need to be conducted to throw a stable conclusion. $[63,64,9]$

5.Research gaps and methods to address the gaps- Although several studies invitro and in vivo are made to understand the mechanism of CAP treatment in cancer cells and positive results have come up. But to clinically prove its significance, the trials should be made on human patients. Though reports of clinical trials are very convincing till date, the reported studies are still limited and are required to be performed on different cancer cell lines. This gap can be overcome by engaging more in clinical research and studies related to CAP treatment on different cancer cell types considering different physiological, physical and chemical parameters of the cells and the plasma respectively.

6.Main Findings- Reactive Oxygen and Nitrogen Species (RONS) is the main entity that contribute to CAPs anticancer activity. RONS creates increased oxidative stress in tumor cells, this causes the CAP to selectively kill cancer cells. The cells are mostly killed by apoptosis and occasionally due to necrosis and senescence. Apart from this, the cancer cells also show immunogenic antitumor activity upon CAP treatment. Furthermore, along with the in vivo and invitro studies, clinical studies (till date) also give quite convincing results with minor or no side effects.

\section{Conclusion and Future Prospects}

Reactive oxygen and nitrogen species (RONS) have been identified as the main contributors for the efficacy of CAP in killing oral cancer cells. However, many studies indicate a selective effect of CAP towards malignant cells compared to their healthy counterparts the experimental settings in many of these studies may have influenced this finding. Furthermore, several factors have been identified that often differ between healthy and malignant cells and hence, may contribute to an increased sensitivity of cancer cells to CAP. Factors such as expression of aquaporins, cholesterol or the ability to protect against oxidative stress by the anti-oxidative system determine how many RONS can enter the cell and interfere with intracellular signaling pathways. CAP treatment often results in reduced adhesion, migration and invasion and may contribute to a successful cancer treatment by reducing the ability of the cells to spread and form metastasis. Furthermore, necrosis, apoptosis, senescence, and autophagy may result from CAP treatment in a dose-dependent manner and hence, stop tumor growth and trigger an immune response. The underlying mechanisms that decide which process of growth arrest or cell death as a consequence of CAP treatment is triggered still need to be further elucidated. Moreover, the different plasma sources and treatment conditions as well as cell types and tumor entities investigated contribute to the efficacy and always need to be considered when drawing any 


\section{OSF PREPRINTS}

conclusions. In the end, great progress has been made to the understanding of underlying mechanisms regarding the efficacy of CAP in cancer treatment, but much still needs to be done with respect to different treatment conditions and comparison of malignant and non-malignant cells of the same cell type and same donor. First clinical case reports support the benefits of CAP as a potential innovative therapy for the treatment of cancers and should motivate further clinical trials to prove the relevance of CAP in the clinic. 


\section{OSF PREPRINTS}

\section{Reference}

1. National Institute of Cancer Prevention and Research(NICPR),2018.

2."Defining Cancer". National Cancer Institute, 17 September,2007.Retrieved 28 March 2018.

3. Choi S, Myers JN. Molecular pathogenesis of oral squamous cell carcinoma: implications for therapy J Dent Res 2008; 87: 14-32.

4. Biscop E., Lin A., van Boxem W., van Loenhout J., Backer J.D., Deben C., Dewilde S., Smits E., Bogaerts A.A. Influence of Cell Type and Culture Medium on Determining Cancer Selectivity of Cold Atmospheric Plasma Treatment. Cancers (Basel) 2019;11:1287.

5. M. Vandamme, E. Robert, S. Lerondel, V. Sarron, D. Ries, S. Dozias, J. Sobilo, D.

Gosset, C. Kieda, B. Legrain, J.M. Pouvesle, A.L. Pape, Int. J. Cancer 130 (2012) 2185-2194.

6. G. Fridman, G. Friedman, A. Gutsol, A.B. Shekhter, V.N. Vasilets, A. Fridman, Applied plasma medicine, Plasma Process. Polym. 5 (2008) 503-533.

7. S. Pereira, E. Pinto, P.A. Ribeiro, S. Sério . Study of a Cold Atmospheric Pressure Plasma jet device for indirect treatment of Squamous Cell Carcinoma. CEFITEC, Departamento de Física, Faculdade de Ciências e Tecnologia, Universidade Nova de Lisboa, 2829-516 Caparica, Portugal.

8 A. Fridman, Plasma Chemistry, 1st Ed., Cambridge University Press, 2008.

9. T. Von Woedtke, S. Reuter, K. Masur, K.D. Weltmann, Plasmas for medicine, Phys. Rep. 530 (2013) 291-320.

10. Chauvin, Julie \& Judée, Florian \& Yousfi, Mohammed \& Vicendo, Patricia \& Merbahi, Nofel. (2017). Analysis of reactive oxygen and nitrogen species generated in three liquid media by low temperature helium plasma jet. Scientific Reports. 7. 10.1038/s41598-017-04650-4. 


\section{OSF PREPRINTS}

11. Yan D., Talbot A., Nourmohammadi N., Sherman J.H., Cheng X., Keidar M. Toward understanding the selective anticancer capacity of cold atmospheric plasma-a model based on aquaporins (Review) Biointerphases. 2015;10:040801

12 Guerrero-Preston R., Ogawa T., Uemura M., Shumulinsky G., Valle B.L., Pirini F., Ravi R., Sidransky D., Keidar M., Trink B. Cold atmospheric plasma treatment selectively targets head and neck squamous cell carcinoma cells. Int. J. Mol. Med. 2014;34:941-946.

13 Biscop E., Lin A., van Boxem W., van Loenhout J., Backer J.D., Deben C., Dewilde S., Smits E., Bogaerts A.A. Influence of Cell Type and Culture Medium on Determining Cancer Selectivity of Cold Atmospheric Plasma Treatment. Cancers (Basel) 2019;11:1287. doi: 10.3390/cancers11091287

14. Yan D., Xiao H., Zhu W., Nourmohammadi N., Zhang L.G., Bian K., Keidar M. The role of aquaporins in the anti-glioblastoma capacity of the cold plasma-stimulated medium. J. Phys. D Appl. Phys. 2017;50:055401. doi: 10.1088/1361-6463/aa53d6.

15.Agre P., King L.S., Yasui M., Guggino W.B., Ottersen O.P., Fujiyoshi Y., Engel A., Nielsen S. Aquaporin water channels-from atomic structure to clinical medicine. J. Physiol. 2002;542:316. doi: 10.1113/jphysiol.2002.020818.

16. Wu B., Beitz E. Aquaporins with selectivity for unconventional permeants. Cell. Mol. Life Sci. 2007;64:2413-2421. doi: 10.1007/s00018-007-7163-2.

17. Almasalmeh A., Krenc D., Wu B., Beitz E. Structural determinants of the hydrogen peroxide permeability of aquaporins. FEBS J. 2014;281:647-656. doi: 10.1111/febs.12653.

18. Bienert G.P., Chaumont F. Aquaporin-facilitated transmembrane diffusion of hydrogen peroxide. Biochim. Biophys. Acta. 2014;1840:1596-1604. doi: 10.1016/j.bbagen.2013.09.017.

19. Miller E.W., Dickinson B.C., Chang C.J. Aquaporin-3 mediates hydrogen peroxide uptake to regulate downstream intracellular signaling. Proc. Natl. Acad. Sci. USA. 2010;107:1568115686. doi: 10.1073/pnas.1005776107. 


\section{OSF PREPRINTS}

20. Trachootham D., Alexandre J., Huang P. Targeting cancer cells by ROS-mediated mechanisms: A radical therapeutic approach? Nat. Rev. Drug Discov. 2009;8:579-591. doi: $10.1038 / \mathrm{nrd} 2803$.

21 Bignon E., Allega M.F., Lucchetta M., Tiberti M., Papaleo E. Computational Structural Biology of S-nitrosylation of Cancer Targets. Front. Oncol. 2018;8:272. doi: 10.3389/fonc. 2018.00272

22. Graves D.B. The emerging role of reactive oxygen and nitrogen species in redox biology and some implications for plasma applications to medicine and biology. J. Phys. D Appl. Phys. 2012;45:263001. doi: 10.1088/0022-3727/45/26/263001.

23. Ahn H.J., Kim K.I., Kim G., Moon E., Yang S.S., Lee J.S. Atmospheric-pressure plasma jet induces apoptosis involving mitochondria via generation of free radicals. PLoS ONE. 2011;6:e28154. doi: 10.1371/journal.pone.0028154.

24. Görlach A., Bertram K., Hudecova S., Krizanova O. Calcium and ROS: A mutual interplay. Redox Biol. 2015;6:260-271. doi: 10.1016/j.redox.2015.08.010.

25. Schneider C., Gebhardt L., Arndt S., Karrer S., Zimmermann J.L., Fischer M.J.M., Bosserhoff A.K. Cold atmospheric plasma causes a calcium influx in melanoma cells triggering CAP-induced senescence. Sci. Rep. 2018;8:10048. doi: 10.1038/s41598-018-28443-5.

26. Deniaud A., Sharaf el dein O., Maillier E., Poncet D., Kroemer G., Lemaire C., Brenner C. Endoplasmic reticulum stress induces calcium-dependent permeability transition, mitochondrial outer membrane permeabilization and apoptosis. Oncogene. 2008;27:285-299. doi: 10.1038/sj.onc. 1210638

27. Itooka K., Takahashi K., Kimata Y., Izawa S. Cold atmospheric pressure plasma causes protein denaturation and endoplasmic reticulum stress in Saccharomyces cerevisiae. Appl. Microbiol. Biotechnol. 2018;102:2279-2288. doi: 10.1007/s00253-018-8758-2.

28. Kumara R., Susara M.H., Piao M.J., Kang K.A., Ryu Y.S., Park J.E., Shilnikova K., Jo J.O., Mok Y.S., Shin J.H., et al. Non-thermal gas plasma-induced endoplasmic reticulum stress mediates apoptosis in human colon cancer cells. Oncol. Rep. 2016;36:2268-2274. doi: 10.3892/or.2016.5038. 


\section{OSF PREPRINTS}

29. Naon D., Scorrano L. At the right distance: ER-mitochondria juxtaposition in cell life and death. Biochim. Biophys. Acta (BBA)-Mol. Cell Res. 2014;1843:2184-2194. doi:

10.1016/j.bbamcr.2014.05.011

30. Raturi A., Simmen T. Where the endoplasmic reticulum and the mitochondrion tie the knot: The mitochondria-associated membrane (MAM) Biochim. Biophys. Acta (BBA)-Mol. Cell Res. 2013;1833:213-224. doi: 10.1016/j.bbamcr.2012.04.013.

31. Andreyev A., Fiskum G. Calcium induced release of mitochondrial cytochrome c by different mechanisms selective for brain versus liver. Cell Death Differ. 1999;6:825-832. doi: 10.1038/sj.cdd.4400565

32. Bekeschus S., von Woedtke T., Kramer A., Weltmann K.-D., Masur K. Cold Physical Plasma Treatment Alters Redox Balance in Human Immune Cells. Plasma Med. 2013;3:267278. doi: 10.1615/PlasmaMed.2014011972.

33. Alkawareek M.Y., Gorman S.P., Graham W.G., Gilmore B.F. Potential cellular targets and antibacterial efficacy of atmospheric pressure non-thermal plasma. Int. J. Antimicrob. Agents. 2014;43:154-160. doi: 10.1016/j.ijantimicag.2013.08.022

34. Han X., Cantrell W.A., Escobar E.E., Ptasinska S. Plasmid DNA damage induced by helium atmospheric pressure plasma jet. Eur. Phys. J. D. 2014;68:46. doi: 10.1140/epjd/e2014-40753-y 35. Ptasińska S., Bahnev B., Stypczyńska A., Bowden M., Mason N.J., Braithwaite N.S.J. DNA strand scission induced by a non-thermal atmospheric pressure plasma jet. Phys. Chem. Chem. Phys. 2010;12:7779-7781. doi: 10.1039/c001188f.

36. Guo L., Zhao Y., Liu D., Liu Z., Chen C., Xu R., Tian M., Wang X., Chen H., Kong M.G. Cold atmospheric-pressure plasma induces DNA-protein crosslinks through protein oxidation. Free Radic. Res. 2018;52:783-798. doi: 10.1080/10715762.2018.1471476

37. Wiseman H., Halliwell B. Damage to DNA by reactive oxygen and nitrogen species: Role in inflammatory disease and progression to cancer. Pt 1Biochem. J. 1996;313:17-29. doi: 10.1042/bj3130017.

38. Breimer L.H. Molecular mechanisms of oxygen radical carcinogenesis and mutagenesis: The role of DNA base damage. Mol. Carcinog. 1990;3:188-197. doi: 10.1002/mc.2940030405. 


\section{OSF PREPRINTS}

39. Gewirtz D.A. A critical evaluation of the mechanisms of action proposed for the antitumor effects of the anthracycline antibiotics adriamycin and daunorubicin. Biochem.

Pharmacol. 1999;57:727-741. doi: 10.1016/S0006-2952(98)00307-4.

40. Han X., Klas M., Liu Y., Sharon Stack M., Ptasinska S. DNA damage in oral cancer cells induced by nitrogen atmospheric pressure plasma jets. Appl. Phys. Lett. 2013;102:233703. doi: $10.1063 / 1.4809830$

41. Chang J.W., Kang S.U., Shin Y.S., Kim K.I., Seo S.J., Yang S.S., Lee J.-S., Moon E., Baek S.J., Lee K., et al. Non-thermal atmospheric pressure plasma induces apoptosis in oral cavity squamous cell carcinoma: Involvement of DNA-damage-triggering sub-G(1) arrest via the ATM/p53 pathway. Arch. Biochem. Biophys. 2014;545:133-140. doi:

10.1016/j.abb.2014.01.022

42. Arndt S., Wacker E., Li Y.-F., Shimizu T., Thomas H.M., Morfill G.E., Karrer S., Zimmermann J.L., Bosserhoff A.-K. Cold atmospheric plasma, a new strategy to induce senescence in melanoma cells. Exp. Dermatol. 2013;22:284-289. doi: 10.1111/exd.12127.

43. Ishaq M., Bazaka K., Ostrikov K. Intracellular effects of atmospheric-pressure plasmas on melanoma cancer cells. Phys. Plasmas. 2015;22:122003. doi: 10.1063/1.4933366

44. Ledford H., Else H., Warren M. Cancer immunologists scoop medicine Nobel prize. Nature. 2018;562:20-21. doi: 10.1038/d41586-018-06751-0.

45. Bekeschus S., Clemen R., Metelmann H.-R. Potentiating anti-tumor immunity with physical plasma. Clin. Plasma Med. 2018;12:17-22. doi: 10.1016/j.cpme.2018.10.001.

46. Khalili M., Daniels L., Lin A., Krebs F.C., Snook A.E., Bekeschus S., Bowne W.B., Miller V. Non-Thermal Plasma-Induced Immunogenic Cell Death in Cancer: A Topical Review. J. Phys. D Appl. Phys. 2019;52:17. doi: 10.1088/1361-6463/ab31c1.

47. Bekeschus S., Seebauer C., Wende K., Schmidt A. Physical plasma and leukocytes-immune or reactive? Biol. Chem. 2018;400:63-75. doi: 10.1515/hsz-2018-0224.

48. Nowarski R., Gagliani N., Huber S., Flavell R.A. Innate immune cells in inflammation and cancer. Cancer Immunol. Res. 2013;1:77-84. doi: 10.1158/2326-6066.CIR-13-0081. 


\section{OSF PREPRINTS}

49. Miller V., Lin A., Fridman G., Dobrynin D., Fridman A. Plasma Stimulation of Migration of Macrophages. Plasma Process. Polym. 2014;11:1193-1197. doi: 10.1002/ppap.201400168.

50. Bekeschus S., Schmidt A., Bethge L., Masur K., von Woedtke T., Hasse S., Wende K. Redox Stimulation of Human THP-1 Monocytes in Response to Cold Physical Plasma. Oxid. Med. Cell. Longev. 2016;2016:5910695. doi: 10.1155/2016/5910695

51. Lin A., Truong B., Fridman G., Fridman A.A., Miller V. Immune Cells Enhance Selectivity of Nanosecond-Pulsed DBD Plasma Against Tumor Cells. Plasma Med. 2017;7:85-96. doi: 10.1615/PlasmaMed.2017019666.

52. Kaushik N.K., Kaushik N., Min B., Choi K.H., Hong Y.J., Miller V., Fridman A., Choi E.H. Cytotoxic macrophage-released tumour necrosis factor-alpha (TNF- $\alpha$ ) as a killing mechanism for cancer cell death after cold plasma activation. J. Phys. D Appl. Phys. 2016;49:84001. doi: $10.1088 / 0022-3727 / 49 / 8 / 084001$

53. Shaul M.E., Fridlender Z.G. Tumour-associated neutrophils in patients with cancer. Nat. Rev. Clin. Oncol. 2019;16:601-620. doi: 10.1038/s41571-019-0222-4.

54. Bekeschus S., Winterbourn C.C., Kolata J., Masur K., Hasse S., Bröker B.M., Parker H.A. Neutrophil extracellular trap formation is elicited in response to cold physical plasma. J. Leukoc. Biol. 2016;100:791-799. doi: 10.1189/jlb.3A0415-165RR.

55. Bekeschus S., Kolata J., Muller A., Kramer A., Weltmann K.-D., Broker B., Masur K. Differential Viability of Eight Human Blood Mononuclear Cell Subpopulations After Plasma Treatment. Plasma Med. 2013;3:1-13. doi: 10.1615/PlasmaMed.2014008450

56. Bekeschus S., Rödder K., Schmidt A., Stope M.B., von Woedtke T., Miller V., Fridman A., Weltmann K.-D., Masur K., Metelmann H.-R., et al. Cold physical plasma selects for specific T helper cell subsets with distinct cells surface markers in a caspase-dependent and NF- $\kappa \mathrm{B}-$ independent manner. Plasma Process. Polym. 2016;13:1144-1150. doi: 10.1002/ppap.201600080

57. Bekeschus S., Moritz J., Schmidt A., Wende K. Redox regulation of leukocyte-derived microparticle release and protein content in response to cold physical plasma-derived oxidants. Clin. Plasma Med. 2017;7-8:24-35. doi: 10.1016/j.cpme.2017.07.001. 


\section{OSF PREPRINTS}

58. Xu R., Rai A., Chen M., Suwakulsiri W., Greening D.W., Simpson R.J. Extracellular vesicles in cancer-implications for future improvements in cancer care. Nat. Rev. Clin. Oncol. 2018;15:617-638. doi: 10.1038/s41571-018-0036-9. [

59. Galluzzi L., Buqué A., Kepp O., Zitvogel L., Kroemer G. Immunogenic cell death in cancer and infectious disease. Nat. Rev. Immunol. 2017;17:97-111. doi: 10.1038/nri.2016.107

60. Lin A., Gorbanev Y., Backer J.D., van Loenhout J., van Boxem W., Lemière F., Cos P., Dewilde S., Smits E., Bogaerts A. Non-Thermal Plasma as a Unique Delivery System of ShortLived Reactive Oxygen and Nitrogen Species for Immunogenic Cell Death in Melanoma Cells. Adv. Sci. (Weinh) 2019;6:1802062. doi: 10.1002/advs.201802062.

61. Freund E., Liedtke K.R., van der Linde J., Metelmann H.-R., Heidecke C.-D., Partecke L.-I., Bekeschus S. Physical plasma-treated saline promotes an immunogenic phenotype in CT26 colon cancer cells in vitro and in vivo. Sci. Rep. 2019;9:634. doi: 10.1038/s41598-018-37169-3

62. Lin A., Truong B., Pappas A., Kirifides L., Oubarri A., Chen S., Lin S., Dobrynin D., Fridman G., Fridman A., et al. Uniform Nanosecond Pulsed Dielectric Barrier Discharge Plasma Enhances Anti-Tumor Effects by Induction of Immunogenic Cell Death in Tumors and Stimulation of Macrophages. Plasma Process. Polym. 2015;12:1392-1399

63. Van Loenhout J., Flieswasser T., Freire Boullosa L., de Waele J., van Audenaerde J., Marcq E., Jacobs J., Lin A., Lion E., Dewitte H., et al. Cold Atmospheric Plasma-Treated PBS Eliminates Immunosuppressive Pancreatic Stellate Cells and Induces Immunogenic Cell Death of Pancreatic Cancer Cells. Cancers (Basel) 2019;11:1597.

64. Lin A.G., Xiang B., Merlino D.J., Baybutt T.R., Sahu J., Fridman A., Snook A.E., Miller V. Non-thermal plasma induces immunogenic cell death in vivo in murine CT26 colorectal tumors. Oncoimmunology. 2018;7:e1484978.

65. Azzariti A., Iacobazzi R.M., Di Fonte R., Porcelli L., Gristina R., Favia P., Fracassi F., Trizio I., Silvestris N., Guida G., et al. Plasma-activated medium triggers cell death and the presentation of immune activating danger signals in melanoma and pancreatic cancer cells. Sci. Rep. 2019;9:4099. doi: 10.1038/s41598-019-40637-z. 


\section{OSF PREPRINTS}

68. Lin A., Truong B., Patel S., Kaushik N., Choi E.H., Fridman G., Fridman A., Miller V. Nanosecond-Pulsed DBD Plasma-Generated Reactive Oxygen Species Trigger Immunogenic Cell Death in A549 Lung Carcinoma Cells through Intracellular Oxidative Stress. Int. J. Mol. Sci. 2017;18:966. doi: 10.3390/ijms18050966.

69. Bekeschus S., Rödder K., Fregin B., Otto O., Lippert M., Weltmann K.-D., Wende K., Schmidt A., Gandhirajan R.K. Toxicity and Immunogenicity in Murine Melanoma following Exposure to Physical Plasma-Derived Oxidants. Oxid. Med. Cell. Longev. 2017;2017:4396467. doi: $10.1155 / 2017 / 4396467$.

70. Rödder K., Moritz J., Miller V., Weltmann K.-D., Metelmann H.-R., Gandhirajan R., Bekeschus S. Activation of Murine Immune Cells upon Co-culture with Plasma-treated B16F10 Melanoma Cells. Appl. Sci. 2019;9:660. doi: 10.3390/app9040660.

71. Bekeschus S., Mueller A., Miller V., Gaipl U., Weltmann K.-D. Physical Plasma Elicits Immunogenic Cancer Cell Death and Mitochondrial Singlet Oxygen. IEEE Trans. Radiat. Plasma Med. Sci. 2018;2:138-146. doi: 10.1109/TRPMS.2017.2766027.

72. Metelmann H.-R., Seebauer C., Rutkowski R., Schuster M., Bekeschus S., Metelmann P. Treating cancer with cold physical plasma: On the way to evidence-based medicine. Contrib. Plasma Phys. 2018;58:415-419. doi: 10.1002/ctpp.201700085.

73. Rutkowski R., Schuster M., Unger J., Seebauer C., Metelmann H.R., Woedtke T.V., Weltmann K.D., Daeschlein G. Hyperspectral imaging for in vivo monitoring of cold atmospheric plasma effects on microcirculation in treatment of head and neck cancer and wound healing. Clin. Plasma Med. 2017;7-8:52-57. doi: 10.1016/j.cpme.2017.09.002.

74. Schuster M., Seebauer C., Rutkowski R., Hauschild A., Podmelle F., Metelmann C., Metelmann B., von Woedtke T., Hasse S., Weltmann K.-D., et al. Visible tumor surface response to physical plasma and apoptotic cell kill in head and neck cancer. J. Craniomaxillofac. Surg. 2016;44:1445-1452. doi: 10.1016/j.jcms.2016.07.001

75.Semmler M.L,Schafer S.M.B,Bernhardt T, Fischer T.Molecular mechanism of thr efficacy of cold atmospheric pressure plasma in Cancer Treatment.Cancers (Basel) 2020 Feb; 12(2): 269. Published online 2020 Jan 22. doi: 10.3390/cancers12020269.PMCID: PMC7072164 


\section{OSF PREPRINTS}

76. Metelmann H.-R., Seebauer C., Miller V., Fridman A., Bauer G., Graves D.B., Pouvesle J.M., Rutkowski R., Schuster M., Bekeschus S., et al. Clinical experience with cold plasma in the treatment of locally advanced head and neck cancer. Clin. Plasma Med. 2018;9:6-13. doi: 10.1016/j.cpme.2017.09.001.

77. Metelmann H.-R., Nedrelow D.S., Seebauer C., Schuster M., von Woedtke T., Weltmann K.D., Kindler S., Metelmann P.H., Finkelstein S.E., von Hoff D.D., et al. Head and neck cancer treatment and physical plasma. Clin. Plasma Med. 2015;3:17-23. doi: 10.1016/j.cpme.2015.02.001. 